\title{
Qualitative exploration of the dynamics of women's dietary diversity. How much does economic empowerment matter?
}

\author{
Michael Nnachebe Onah ${ }^{1,2, *}$, John Hoddinott ${ }^{3}$ and Susan Horton ${ }^{1}$ (i) \\ 'School of Public Health and Health Systems, Faculty of Health, University of Waterloo, Waterloo, ON, Canada: \\ ${ }^{2}$ Institute of Public Policy and Administration, Graduate School of Development, University of Central Asia, Bishkek, \\ Kyrgyzstan: ${ }^{3}$ Division of Nutritional Sciences, Cornell Institute of Public Affairs, Cornell University, Ithaca, NY, USA
}

Submitted 11 August 2020: Final revision received 26 August 2021: Accepted 18 November 2021: First published online 29 November 2021

\begin{abstract}
Objective: This study qualitatively examined dietary diversity among married women of reproductive age who engaged in two socio-economic activities to explore the dynamics of food availability, access, costs and consumption.

Design: Qualitative in-depth interviews. The food groups in the Minimum Dietary Diversity for women were used to explore women's dietary diversity. IDI were used to develop a roster of daily food consumption over a week. We explored food items that were considered expensive and frequency of consumption, food items that women require permission to consume and frequency of permission sought and the role of economic empowerment. Data analysis followed an inductivedeductive approach to thematic analysis.

Setting: Rural and peri-urban setting in Enugu State, Nigeria.

Participants: Thirty-eight married women of reproductive age across two socioeconomic groupings (women who work only at home and those who worked outside their homes) were recruited in April 2019.

Results: Economic empowerment improved women's autonomy in food purchase and consumption. However, limited income restricted women from full autonomy in consumption decisions and access. Consumption of non-staple food items, especially flesh proteins, would benefit from women's economic empowerment, whereas staple food items would not benefit so much. Dietary diversity is influenced by food production and purchase where factors including seasonal variation in food availability, prices, contextual factors that influence women's autonomy and income are important determinants.

Conclusion: With limited income, agency and access to household financial resources coupled with norms that restrict women's income earning, women continue to be at risk for not achieving adequate dietary diversity.
\end{abstract}

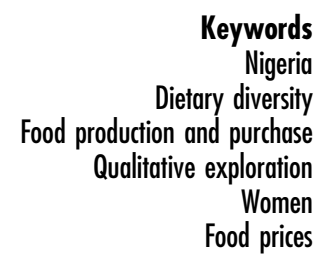

Economic empowerment for women has been identified as a key strategy for improving women's ability to exert autonomy (ability and capacity to make choices) and agency (ability to act on choices) in access to welfare-improving resources at individual and household levels ${ }^{(1,2)}$. Improving women's income earning potential has been identified as a sustainable means of economic empowerment. However, in many rural settings in low- and middle-income countries (LMIC), economic opportunities are limited, and there are existing contextual norms that restrict women from gaining full empowerment and ability to act on empowerment gains ${ }^{(3,4)}$. These economic and contextual factors further restrict the extent to which women can exert agency

and autonomy in unhindered access to and consumption of household resources including food.

Improving the nutrition status and dietary diversity of women has been a major focus of development interventions $^{(5)}$, since better diets improve not only health and nutrition, but also have economic benefits via work and productivity $^{(6,7)}$. The Minimum Dietary Diversity for women (MDD-W) of reproductive age examines whether or not women of age 15-49 years have consumed at least five out of ten defined food groups the previous day or night ${ }^{(8)}$. The measure is also used as a proxy for nutrient adequacy of the diet of women. Different foods and food groups are good sources for various macro- and

*Corresponding author: Email chebis.onah@gmail.com

(c) The Author(s), 2021. Published by Cambridge University Press on behalf of The Nutrition Society. This is an Open Access article, distributed under the terms of the Creative Commons Attribution-NonCommercial-ShareAlike licence (https://creativecommons.org/licenses/by-nc-sa/4.0/), which permits non-commercial re-use, distribution, and reproduction in any medium, provided the same Creative Commons licence is included and the original work is properly cited. The written permission of Cambridge University Press must be obtained for commercial re-use. 
micronutrients, and so a diverse diet best ensures nutrient adequacy $^{(9)}$. Foods are commonly grouped into categories such as energy-dense carbohydrates, plant-based protein-rich sources of micronutrients including legumes, nuts and seeds and flesh-based proteins. Numerous studies have utilised the MDD-W measure to find a strong link between improved dietary diversity and health outcomes $^{(6,9-11)}$. Evidence also suggests that there are many determinants of improved dietary diversity for women with different contextual factors playing an important role in women's food consumption ${ }^{(9,12,13)}$.

The household cooperative conflict model suggests that individuals within households have different access to resources, including food, based on multiple factors which include their economic and social status and beliefs ${ }^{(14,15)}$. Evidence suggests that while financial resources might be pooled for certain categories of expenditures, existing norms tend to influence expenditure responsibilities between men and women ${ }^{(16-19)}$. While men tend to be more responsible for large and more expensive purchases including healthcare and certain food expenditures, women are more likely to be incharge of smaller purchases including daily staple food expenditures ${ }^{(20,21)}$. In rural LMIC, these gendered expectations also extend to agriculture and determines who does what. While men are more likely to be responsible for decisions regarding 'men's crops' which are often cash crops, women tend to be incharge of 'food crops' which are often staple foods ${ }^{(10,22,23)}$. In the context of food consumption decisions, cultural beliefs also play an important role in defining what constitutes adequate food and nutritional needs for different household members ${ }^{(24,25)}$. For instance, $\operatorname{Gupta}^{(26,27)}$ argues that in Asia, even when household diets are adequate, women tend to consume a less diverse diet which is not enough to meet their daily nutritional needs which could be elevated by pregnancy, lactation and heavy workloads. Men or older women in the household often exert control over what young women and mothers consume.

The cultural context of Nigeria is similar to that of many LMIC, especially in sub-Saharan Africa and West Africa. In rural settings, agriculture is the mainstay economic activity for households with a gendered division of labour. However, as in many West African countries, there are significant variations in cultural practices within the country ${ }^{(28)}$. In the North, Islam is the prevalent religion with associated norms including high rates of polygamy and lower rates of indicators that ensure better empowerment for women including education and a larger age gap between married men and women ${ }^{(29-31)}$. In the South, Christianity is the prevalent religion and while polygamy is not uncommon, monogamy is the prevalent marriage practice $^{(28)}$. In rural societies in Nigeria like in many LMIC, norms exist that tend to be anchored on patriarchy, patrilineality and patrilocality and expectations that favour males ${ }^{(24,26,32)}$. These norms create gender biases that limit women from unhindered access to household resources including food ${ }^{(25)}$. Since men are regularly expected to be the primary income earners and decision-makers in these societies, women often grapple with negotiating access to household food resources to ensure adequate quantity and quality of food consumed.

Economic empowerment through income generation has been identified as a key strategy for women to improve their dietary diversity ${ }^{(1,9,33)}$ especially if women's access to and custody of earnings improves ${ }^{(10)}$. Studies have suggested a link between women's economic empowerment, ability to negotiate better access to household resources including food, and improved dietary diversity ${ }^{(25,34,35)}$. However, previous studies have not extensively examined which specific food groups are most affected by improved economic empowerment through income earning for women. This becomes more important since in many rural societies in LMIC, while many economic empowerment initiatives improve women's income generation, usually, the income generated from these activities is not sufficient for women to fully negotiate access to household food resources and consumption decision-making ${ }^{(36)}$.

To fill this gap in knowledge, this study developed a roster of daily food consumption in the past week and examined women's food consumption activities. This study's objective was to qualitatively examine the household-level dynamics of women's dietary diversity using the MDD-W across two socio-economic groupings based on women's income-generating activity.

\section{Methods}

\section{Study setting}

The qualitative study was conducted in Nsukka Local Government Area located in the northern part of Enugu State in south-eastern Nigeria. Nsukka Local Government Area comprises one urban and fourteen rural communities, with a population of almost 310000 , comprising approximately 63705 households ${ }^{(37)}$. Agriculture is the main economic activity, and there is a variety of food items cultivated for subsistence and commercial purposes ${ }^{(38)}$. The predominant ethnic group is Igbo and while traditional religion exists in the study setting, the predominant religion is Christianity.

\section{Data collection instrument}

Our primary focus was on women of reproductive age. We developed a brief roster to collect information on food items produced, purchased and consumed including their annual and weekly availability, respectively. Additional information was collected on food items that were considered too expensive to purchase and frequency of consumption of these food items, as well as food items for which women needed permission from their husband 
before purchase and consumption, and frequency of permission sought. These questions were developed to add more contextual details on women's consumption of food items belonging to the ten food groups as measured by the MDD- $W^{(8)}$. Demographic information collected included age, respondent's and their male spouse's occupation, household structure and number of children including their ages. Interview guides were translated into the local language (Igbo) and piloted to ensure that participants understood the translated questions prior to data collection. More details of the study methodology and instruments can be found in Onah ${ }^{(10)}$.

\section{Data collection and management}

Data were collected between 9th and 24th April 2019 from women who were married or had a live-in partner. Due to consent considerations, the study includes only sampled women of reproductive age between the ages 18 and 49 years. This is inline with the MDD-W guidelines ${ }^{(8)}$ where the dietary diversity measure is only used for women of reproductive age (15-49 years). Participants' recruitment was stratified into two identified socio-economic groups based on their primary economic activity to ensure that we recruited enough participants from each socio-economic group. The stratification was informed by inputs from local stakeholders and experts within the local government in addition to published survey methodologies within the study location ${ }^{(39,40)}$. These published methodologies indicated locations within the study setting where each identified economic activity was most prevalent and was verified by local stakeholders. Two major economic activities were identified based on location: work primarily at home and work outside the home. Since the study setting was predominantly rural, the identified socio-economic groups also both engaged in smallholder agriculture. Location was important since households that were located close to markets tended to have more women engaging in work outside their homes. Thirty-eight in-depth interviews (IDI; nineteen each for two economic groups) in four systematically selected wards within the local government were conducted and households were randomly selected. To limit the possible effects of interviewer bias whereby respondents might not be forthcoming with responses due to the age gap between them and the interviewer, younger interviewers (below 30 years) led IDI involving younger participants (below 30 years) while older interviewers led IDI involving older participants.

IDI were administered to women who self-identified as the female decision-maker and/or primary caregiver within sampled households. This was achieved by asking the first contact within sampled households to identify who was considered as the female decision-maker and/or primary caregiver. Their status was then verified before study commenced. We started each IDI with the collection of socioeconomic and demographic information followed by the completion of the food roster with a 1-week time horizon. Participants were asked to list all food items consumed daily over a week, and these items were matched to a predefined list of food groups. This lasted for $20 \mathrm{~min}$ on average. Next, the frequency of consumption of the listed food items was collected and in-depth questions probed the reason behind consumption patterns. Each IDI lasted for an average of $55 \mathrm{~min}$. The duration was kept closer to the upper time limit suggested for IDI $(60 \mathrm{~min})^{(41)}$ to give participants enough time to fill the roster of food items and also provide in-depth insights into food availability and consumption.

\section{Data analysis}

Data were managed and analysed using NVivo and Microsoft Office Excel, and analysis followed the inductive-deductive approach to thematic analysis (i.e. integrated data-driven and theory-driven coding) ${ }^{(42)}$. This approach complemented the research objective by developing themes that were inline with the ten food groups contained in the MDD-W and by also exploring eight pre-determined themes that explored household-level gendered dynamics related to food access and consumption. Using explicit coding and analytic procedures, data were abstracted under the following themes: (1) food items produced/cultivated; (2) availability of food items produced/ cultivated; (3) food items purchased; (4) availability of food items purchased; (5) food items considered too expensive to purchase; (6) consumption frequency of expensive food items; (7) food items that require permission from spouse to purchase and consume and (8) frequency of permission sought. These themes were explored among women within the two identified socio-economic groupings. New relevant themes that emerged during the review of the transcripts were also captured and coded. Key quotes selected from the IDI were used to represent majority opinion or in some cases, outliers according to topics. An inter-rater reliability test (Cohen's $\kappa)^{(43)}$ was performed by the researcher and research assistant to ensure data was captured consistently in NVivo. This involved conducting a coding comparison by selecting two transcripts to be coded by both capturers within the established coding scheme. The test confirmed a high level of consistency (0.94 Cohen's $\kappa$ ) in the interpretation of data and clarity of the coding scheme.

\section{Results}

\section{Participants' characteristics}

Thirty-eight married women participated in the IDI with an average age of 36.5 years (SD: 9 years). Among participants, $23 \%(n 9)$ were in polygamous households while $77 \%$ ( $n$ 29) were in monogamous households. All participants had a farm and while $80 \%$ ( $n$ 30) of women used their farms both for subsistence and commercial purposes, $20 \%$ used it for subsistence only. All participants had at least one child 
Table 1 Description of food items included in the 10 Minimum Dietary Diversity for women (MDD-W) food groups

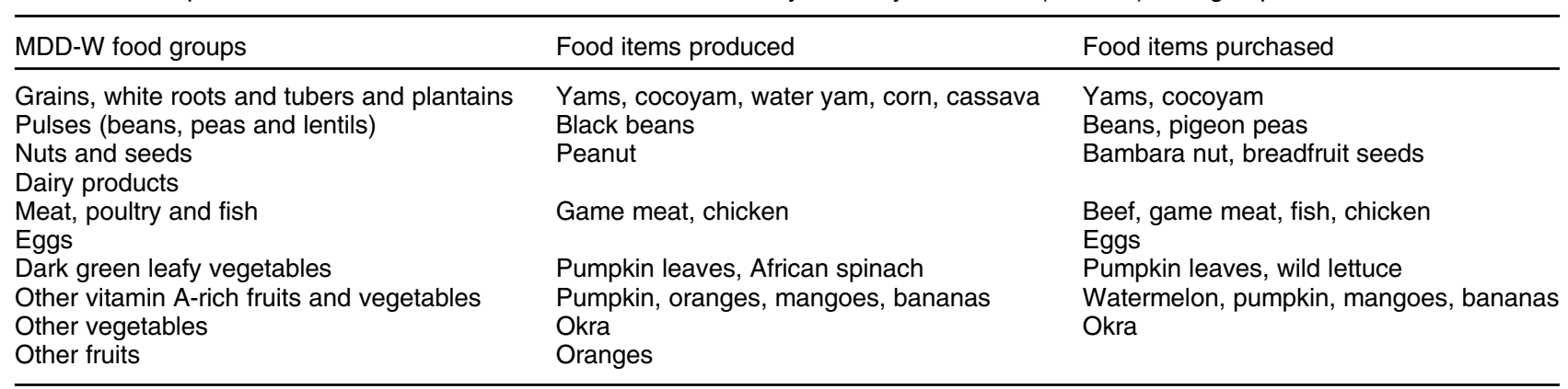

and $50 \%$ ( $n$ 19) had at least one child under 5 years. Fortythree percent $(n 16)$ of women worked outside their homes and farm. Occupations outside the home predominantly included hairdressing and food vending. Male spouses were reported to have two main occupations, namely: farmer only and farmer/market trader while one respondent had a male spouse that engaged in out-of-home periodic construction work.

\section{Food groups produced and purchased across bousebolds}

Participants provided details of food items produced and/or purchased from which we developed a list of food groups based on MDD-W recommendations ${ }^{(8)}$ (see Table 1). Participants largely purchased food items that were not cultivated in the region where the study was conducted. Participants could record more than one food item belonging to a particular food group.

All women reported producing a staple grain and/or root tuber, $30 \%$ reported producing a pulse food item, $10 \%$ reported producing an 'other' vegetable food item and only one individual ( $2 \%$ ) reported producing any food item belonging to nuts and seeds, meat and fish and other fruits food groups. There was no report of households producing food items belonging to eggs and dairy products food groups (see Fig. 1). Food items produced were reported over the year, and data were collected during planting season. While we only examined food availability and consumption, purchasing might be more frequent during the planting season than at some other times of year, although households process and store items produced ${ }^{(44)}$. For food items purchased, we examined current (1 week) purchase of food items as at study time. All participants reported having at least one home-produced grain or tuber at their homes available all year and $17 \%(n 6)$ reported having at least one home-produced pulse available at their homes all year.

Women who engaged in economic activities outside their homes were more likely to purchase food items across the eight food groups in the MDD-W. Ninety-three percent ( $n$ 35) of the women (including all the women who worked outside their home) reported currently purchasing food items belonging to grain, tubers and meat and fish groups.
All women reported currently purchasing at least one pulse food item, $87 \%$ ( $n$ 33) purchased a food item belonging to dark green leafy vegetable food group and $70 \%$ ( $n$ 27) purchased a food item belonging to other vitamin A-rich vegetables food group. There were fewer reports of purchase of eggs (6\%) and other fruits and vegetables (30\%), and no one reported purchasing other fruits and dairy products. Sixtythree percent ( $n$ 24) of the women reported currently purchasing some type of nuts or seeds, with women who worked outside their homes being more likely to purchase these food items.

This study explored the reasons behind households' purchase of food items which they also produce, and participants spoke of a variety of reasons for purchasing additional food items. Identified reasons include seasonality of food items, and crop yield including prevailing pests and diseases affecting crop performance. It is important to note that data were collected 2 weeks after the first rains in the region (in April). This period marks the beginning of planting season and an abundant supply of green vegetables (both cultivated and purchased) and of many fruit varieties ${ }^{(45,46)}$. Also, this period affects the availability and price of certain food items including cassava, yams, beans, game meat, pigeon peas, Bambara nut and breadfruit seeds due to scarcity and the use of some of the items as seeds for planting ${ }^{(45)}$. Participants spoke of how these food items become less available and more expensive in the market during this season relative to post-harvest season. Table 2 contains quotes that illustrate participants' reflections on the availability of food items.

\section{Income generation, bousebold food purchase and consumption frequency}

Generally, women who worked outside their homes and farms had better access to financial resources and reported improved autonomy in food purchase, and better dietary diversity for themselves. To explore the role of income generation on food purchase and consumption, women were asked to elaborate on the issues about food purchase using household or individual incomes. Women identified personal and children's needs as a determinant of food purchases (see Table 3). These include the need for variety in food consumption, perceived health benefits of diversity 

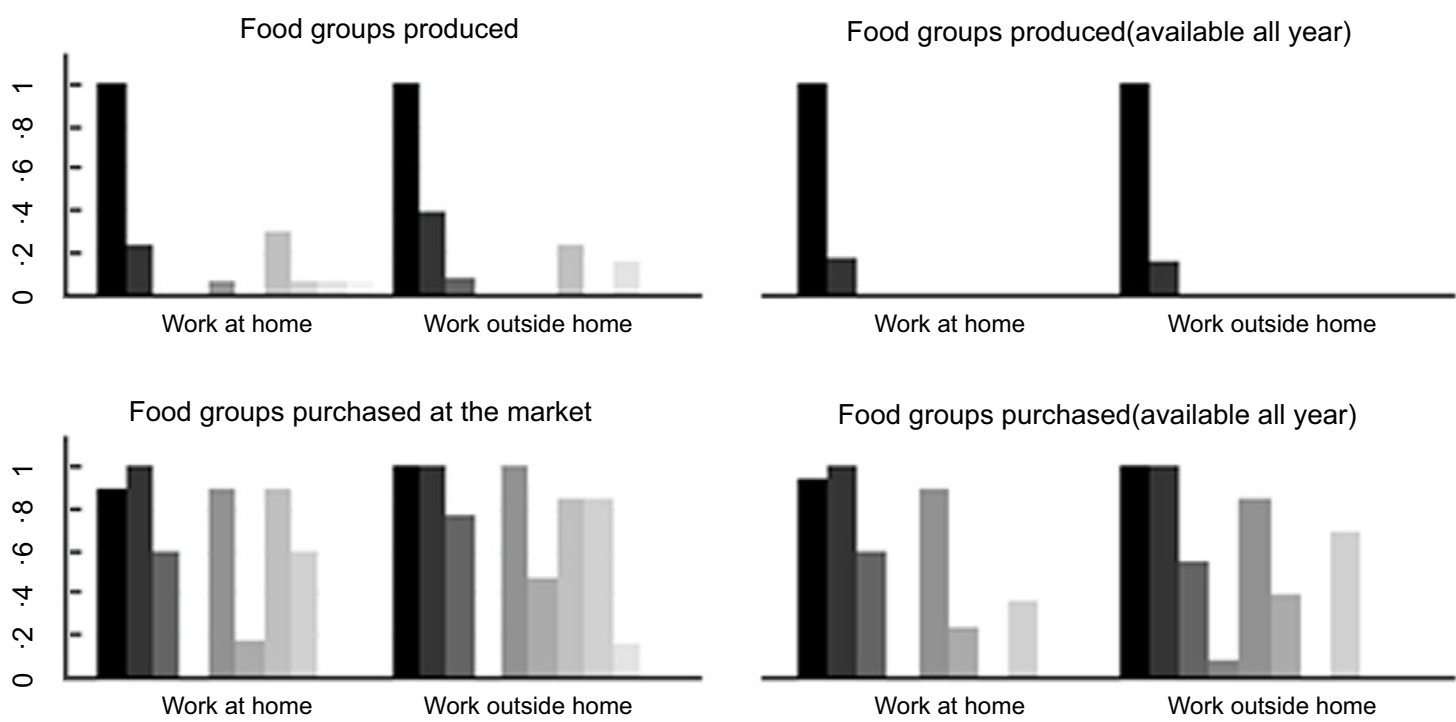

\begin{tabular}{|l|l|}
\hline Group 1(Grains/Tubers) & Group 2(Pulses) \\
Group 3 Nuts/Seeds) & Group 4(Dairy) \\
Group 5(Meat/Fish) & Group 6(Eggs) \\
Group 7(Dark green vegs) & Group 8(Vit A-rich fruits/vegs) \\
Group 9(Other vegs) & Group 10(Other fruits) \\
\hline
\end{tabular}

Fig. 1 Characteristics of food groups consumed across households

in food consumption and perceived malnutrition status of themselves and their children as reasons for increasing the purchase and consumption of green vegetables and flesh proteins. There is an apparent divide, in that women who engaged in economic activities outside their homes reported greater autonomy in decisions regarding food consumption and better dietary diversity. However, these outside activities generated limited income as identified by participants, hence this limited women's ability to exhibit fully agency in food consumption since incomes generated are usually not enough for the purchase of certain food items. Women spoke of the need to ask for additional household income to supplement their personal incomes and how this dynamic could determine the frequency of food purchase and consumption. The quotes in Table 3 summarise participant's reflections on food purchase and consumption.

\section{Food costs, bousebold decision-making and consumption frequency}

To explore the relationship between food prices and consumption, participants were asked to identify food items they considered to be too expensive and their consumption patterns of such items. There was a clear divide between the two groups of women in food groups considered too expensive to consume and their consumption frequency (see Fig. 2). Women who worked at home and on farms only ( $n$ 22) were more likely to report items too expensive to consume $(50 \%$ reported this for grains and tubers, $90 \%$ for legumes and pulses, $40 \%$ for nuts and seeds and $100 \%$ flesh proteins) as compared to $20 \%, 50 \%, 30 \%$ and $90 \%$, respectively, of women who also worked outside the home. Further, when frequency of consumption of expensive food groups was examined, $10 \%$ of the women who worked at home and on farms only consumed these food items regularly, $40 \%$ occasionally and $60 \%$ rarely. For women who worked outside their homes in addition to farming, $38 \%$ consumed food items considered to be too expensive regularly, $47 \%$ consumed these food items occasionally and $15 \%$ consumed these food items rarely.

A similar pattern was observed when asking about when permission was required to consume expensive items and frequency of seeking such permission (Fig. 2). While $75 \%$ of the women who worked at home and on farms only and $50 \%$ of those that worked outside their homes in addition to farming required permission sometimes to purchase and consume these expensive food items, $8 \%$ of the women who worked outside their homes in addition to farming and $23 \%$ of those that worked only at home and on farms required permission always.

Women spoke of the different dynamics that lead to the need to obtain permission before certain food items are consumed. While women that engaged in income-generating economic activities outside their homes in addition to farming reported improved autonomy in making 
Table 2 Sample quotes on food availability

1. You know for some time now there is this pest (Pythium myriotylum) that kills cocoyam around June/July when they should be growing nicely in the farms. So, people that have access to rivers start farming cocoyam in January and harvest it this time. They bring it to the market so that people that want to eat and also use the tiny ones as planting seeds can buy them. There is too much competition for it now, so the prices are too high. - 23-year-old, smallholder farmer only

2. Vegetables are now many in the market and very cheap due to the rains that started falling 2-3 weeks ago so anyone can buy it now. It gets scarcer and more expensive in the dry season. - 29-year-old, smallholder farmer and hairdresser

3. We plant yams in our farms, but you know the yield is always small compared to those that they bring from the North. And now yam season is gone coupled with those buying to use them to plant so the price is very high and only a few of us can buy some for eating. - 30-year-old, smallholder farmer only

4. When the rain starts, game meat becomes very scarce because you know they hunt for the animals by burning the bushes during dry season so the price of it now is too high. - 44-year-old, smallholder farmer and food vendor

5. We plant black beans here but buy the white ones in the market. The black beans are used to make food that are different from the ones you can make with white beans and since we don't plant white beans here, we buy it. It can be expensive depending on when you go to the market. - 20-year-old, smallholder farmer and food vendor

6. Cassava is available anytime of the year and cheap. It is either you get them raw, or you make or buy garri (made from cassava) whenever you need it. But you know you cannot eat cassava alone; you still need to spend money to buy fish to make a soup. Good thing is that fish is not as expensive as beef or chicken. - 36-year-old, smallholder farmer only

Table 3 Sample quotes from women on food purchase and consumption

General quotes from smallholder farmers $(n$ 22)

1. For those of us that do not work, it is hard for us to just go to the market and buy food items. We must ask our husbands first and what they feel is important is what we buy. Many men will just give you the money and then you decide what to buy but there are men who will also tell you how much to spend on each item.... I am sure that women who work will not experience the same.

2. For the fact that you don't make money, men will value you less and will only give you how much they think you need to buy food even when they are eating the same food. I think my husband eats outside before he gets back from work. That is the only way I can explain him allowing myself and the children to eat such poor food.

3. Most times you see people eating mostly cassava, cocoyam and dry corn because they are cheaper than other food items. My husband is a construction worker, and he believes in eating cassava in the morning for energy and since it can sustain him until evening. I don't like it but since I don't make money, I have little say.

Quotes restricted to employed women (food vendors and hairdressers)/farmers ( $n$ 16)

1. When I feel that I am getting too thin or frail or when my children start looking too hungry, I buy more vegetables, beans, and meat. I usually don't wait for my husband because I have the money. Sometimes, I need to ask him too because meat and other items like breadfruit seeds can be too expensive, and I don't make enough money from my business.

2. Sometimes what we make is not enough to buy all food items we choose. We need to depend on our husbands for money. I don't like asking for money because he (husband) usually makes me to give account of my expenditure and then he would always say that fish or meat should be eaten once a week. That is not right but what can I do? ... I wish I made more money

3. I am happy I make my own money, this way, I can take better care of myself and my children and eat better food that is good for our health. You will be surprised by how many women that are not allowed to eat what they feel their bodies need because they do not work. Although sometimes even those that work experience the same issues.

4. We as women know the need to eat a balanced diet made of different food items, but money is always the problem. I use my money to buy cheaper items like vegetables and beans, but my husband buys expensive items like meat. This way, we can eat food that will make us strong.

decisions regarding the consumption of expensive food items including frequency of consumption relative to those that worked at home and on farms only, due to their limited income, autonomy in food access and decision-making was also restricted (see Table 4). Women typically required permission before purchasing and/or consuming expensive food items. Women spoke of food prices being an important factor that led to the need to seek for financial support and permission from their husbands. The quotes in Table 4 illustrate household dynamics and how they affect the purchase and consumption of certain food items.

\section{Other bousebold dynamics that affect women's dietary diversity}

The present study recruited women of reproductive age and $27 \%$ ( $n$ 10) of them were breastfeeding at the time of data collection. Also, 23\% ( $n$ 9) of the participants lived in polygamous households. These dynamics played a role in different approaches to food consumption and dietary diversity. Lactating women spoke of being encouraged by their husbands to consume more diverse food items including more green vegetables and eggs to enable them to breastfeed adequately. Within polygamous households, women spoke of the influence of marital and social conflict ${ }^{(47)}$ on their ability to improve their dietary practices. These conflicts had economic implications for their actions, with some of them withholding income from working and sale of food harvests. Table 5 provides more insight into these household-level dynamics.

\section{Discussion}

The findings from this study provide evidence that complement existing literature on women's dietary diversity from 

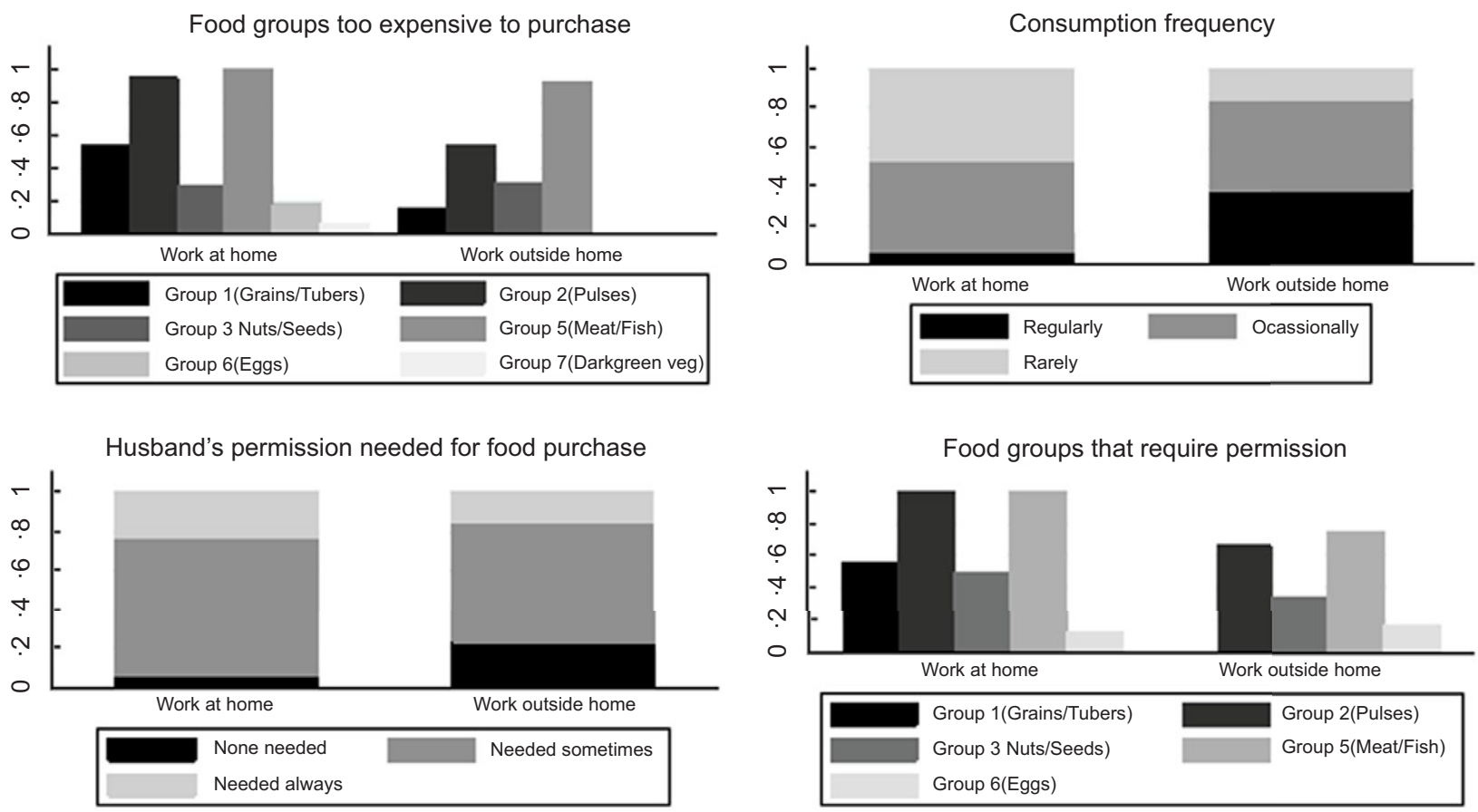

Fig. 2 Expensive food groups and consumption frequency

Table 4 Sample quotes from women on permission to consume food items and frequency of permission sought

General quotes from smallholder farmers $(n$ 22)

1. Where is the money for fancy (expensive) food? I don't work, and my husband is rarely at home due to work, we manage with the little food that he gave me money to buy until when he comes back from working on the highway, that is when we get to eat better....I am sure many women like myself experience this.

2. Some food items like meat, eggs, and breadfruit are important but very expensive, so we only eat them when my husband asks me to buy them which is not often.... If I had my own money, I could maybe buy it more often.

3. My son is very good at hunting game meat, but my husband will always want to sell it. He always gives me a part of the money for my personal use and to buy nice food like breadfruit seeds.

Quotes restricted to employed women (food vendors and hairdressers)/farmers $(n 16)$

1. The money I make from hairdressing is not even enough to buy some food items like chicken and pigeon peas. I need to collect more money from my husband. He will always ask what it is for and I will need to explain first.... we don't eat chicken often, so I don't always worry about asking him for money.

2. Since I buy most of the food items at home with my money, I don't ask for permission most times for us (woman and children) to consume the expensive food items like meat that my husband buys. There are times when permission is needed like during the week.

3. Having my own money is good. Now, I can buy some food items that are good for me like beans and cow pea, not the everyday cassava or corn flour that my husband prefers we eat.

Table 5 Other household dynamics that affect women's dietary diversity

1. I just had a baby, so my husband brought one of his sisters to come and stay with us for a while. She prepares for me whatever I want to see so that I can produce more milk. - 22-year-old, smallholder farmer only

2. I am still breastfeeding, so my husband ensures that I eat fruits and vegetables as much as I want. He even buys them for me. I am enjoying it for now since you know these things change once the baby grows and stops breastfeeding. -30 -year-old, smallholder farmer and hairdresser

3. My younger co-wife has all my husband's attention, so to be able to compete, I need to eat well and look good. Good enough, I hold the money I make from sales. I don't give it to my husband anymore. - 44-year-old, smallholder farmer and food vendor

4. My husband does not take care of me anymore since he married his new wife. I cater for myself and if I don't work hard, I won't be able to feed myself. - 40-year-old, smallholder farmer and food vendor

known dietary diversity measures. The findings suggest that women's dietary diversity can be influenced by household and market determinants including food availability and prices, where food prices are most important for items that are not produced within households. Seasonal factors including rainfall and pests also affect food availability and crop yield which has an impact on food prices and consumption for women. The interaction between food prices 
and availability, and women's dietary diversity appear in two ways. Firstly, the availability of certain food items within a household is influenced by their costs in the market, and consequently, women reported reduced consumption frequency. Secondly, due to the cost of these food items, women need to seek for access to financial resources and permission to consume such items and are unable to consume them when their male counterparts are away from home. This is more significant for women who do not have an independent source of income. This study findings argue further that the 'broad' statements from quantitative studies that suggest a strong empowerment diet link across different empowerment domains may only matter for a much narrower list of food items. For instance, studies have found that a unit increase in empowerment scores across different domains is associated with increases in the probability of improved dietary diversity and nutrition outcomes ${ }^{(10,48,49)}$ however, such associations might matter for a narrower list of food items. While Onah et al. ${ }^{(13)}$ using quantitative means found varied associations between empowerment domains and the consumption of specific food groups for women, this study goes further by qualitatively examining the socio-economic nuances that inform some of these varied quantitative associations.

Negotiating improved access to household food resources was improved by women's economic empowerment through income generation since there was a mediating role of economic empowerment towards the consumption of certain food items, especially flesh proteins and certain legumes, nuts and seeds. This suggests that economic empowerment for women might have a differential impact on women's ability to access and consume different food groups. The restrictive nature of limited income generation on women's ability to negotiate food access and achieve adequate diversity in their diets has further implications. Although improved economic empowerment appears to play a significant role in improving women's ability to consume the more expensive food items, the increase is often not enough to allow women to achieve the desired level of access to these food items. Higher but still insufficient income limits their ability to achieve adequate dietary diversity. This addition to the literature is important since we could not identify a study that has suggested this insight into women's dietary diversity.

On the other hand, it appears that women's economic empowerment would not have much impact on access to and consumption of food items that were staple items (grains and root tubers) since all women consume these regardless of the income-generating status. For fruits and green vegetables, in addition to economic empowerment, there appears to be a need to empower women through improved agricultural practices that would ensure yearround availability of these food items since they are perishable and experience large seasonal variations in availability with resulting fluctuations in market prices.
Our finding of a link between the prices of food items and their consumption frequency is consistent with literature ${ }^{(50-53)}$. Two systematic reviews and meta-analyses by Andreyeva et $a l .{ }^{(54)}$ and Green et al. ${ }^{(55)}$ of over 200 studies in over 170 countries found that: (1) the demand for food was more responsive to price changes among households with lower incomes; (2) the demand for all food groups was more responsive to changes in price in lower income than higher income countries and (3) increasing food prices or falling incomes in a recession create pressure to purchase foods that are lowest in cost. This makes calorie-andenergy-dense foods more attractive since they tend to cost less than other food items and provide needed energy for daily activities. In a peri-urban South African setting, Chakona and Shackleton ${ }^{(9)}$ found that dietary diversity for women in the area was more sensitive to changes in incomes and food prices because women lacked safety nets to absorb income or price shocks, since they depended more on food purchase. This linkage between food prices and access and consumption of diverse diets further highlights the potential role of economic empowerment through income generation on women's ability to exhibit autonomy and agency in access to different food items within households.

While there is limited literature on the relationship between economic empowerment and women's consumption of specific food groups, the relationship between economic empowerment and dietary diversity for women has received some attention in the literature. Findings suggest that improved economic standing for women is associated with better dietary diversity and nutrition outcomes ${ }^{(35,56-61)}$. A few recent studies have also examined seasonal variations in women's dietary diversity ${ }^{(6,62-64)}$ and findings suggest that women's dietary diversity scores tend to decrease during food shortages. Our study confirms the suggestion from these studies and goes a step further by suggesting that while improving dietary diversity through economic empowerment is desirable, further exploration of what empowerment strategies are most important for targeting the consumption of different food groups should be given adequate attention in future research.

Breastfeeding status has been considered an integral part of dietary diversity for infants and children, but the effect on women's dietary diversity has not been considered adequately ${ }^{(65,66)}$. However, there is existing evidence on dietary diversity for lactating women in LMIC, especially regarding food taboos, myths and perceptions ${ }^{(67-70)}$. In rural Mexico, Santos-Torres \& Vásquez-Garibay ${ }^{(69)}$ found that almost half of women examined avoided the consumption of fruits, vegetables and legumes during lactation and this was associated with no prenatal breastfeeding awareness. In a rural setting that is similar to our study setting in South East Nigeria, Ekwochi et al. ${ }^{(71)}$ suggests that women avoided the consumption of certain proteins and legumes due to perceived impact on child growth and development. Our findings are somewhat different since women spoke of 
engaging in improved dietary diversity and the consumption of fruits and vegetables due to their perceived benefits on their health and in turn, that of their children. This is an important observation since many of the studies that examine women's dietary diversity using quantitative measures rarely consider the role of their breastfeeding status.

Also, an important finding is the role of social conflict within polygamous families on women's dietary diversity. This suggests that beyond economic and financial factors, household-level dynamics including social conflict (in our case between co-wives) play a role in women's access to and consumption of different food items. This gives credence to the gender and cooperative conflict model as proposed by Sen ${ }^{(14)}$ where women within households (in our case polygamous households) compete for resources including the attention and affection of their spouses. For this study, improved dietary diversity was used as a tool of cooperative conflict based on its perceived positive effects on health outcomes and physical appearance.

This study acknowledges a few limitations. The generalisation of the findings is limited due to the inherent nature of qualitative studies including the sample size and sampling methodology. Participants were not asked to list the time of year when different food items were more or less available. This would give us a better understanding of the seasonal variations in availability of food items. Also, men's dietary diversity within households was not explored. This could have provided enough information to enable performing a more gendered analysis. This might shed more light into male-female differences in dietary diversity. We did not collect detailed information on other sources of food consumption including gifts and attendance of ceremonies like weddings, which might be an important source of food for women. Our data might suffer from recall bias since women were asked to recall daily food consumption information over a week. We did not examine the effect of nutrition education for the index woman and her male spouse, and this might have an important effect on women's dietary diversity. We also did not examine the effect of respondents' number of children and their gender composition and their male spouses' occupation, and these might play an important role in women's dietary diversity. Nevertheless, to the best of our knowledge, this study is the first to qualitatively probe in depth, the dynamics of women's food consumption as it relates to dietary diversity.

\section{Conclusion}

This study's findings shed light on the need for more indepth understanding of women's dietary diversity and the potential role of qualitative exploration. A disaggregated approach to examining the role of women's empowerment on their dietary diversity is needed since our findings suggest that economic empowerment might be important for improving women's ability to consume some but not all food items. In addition, environmental factors including seasonality should be considered when designing initiatives that aim to improve women's consumption of diverse diets. It is imperative to understand that for many women in LMIC and sub-Saharan Africa, negotiating food consumption through production and purchase is complex, especially when faced with limited personal income, agency and access to household income. Unless economic empowerment improves women's financial resources upto-and-above a threshold where all food items across different food groups are easily affordable, limited income will continue to be a barrier to women's dietary diversity. Efforts should also perhaps consider other non-economic empowerment strategies which might be beneficial. There is the need for further research on the extent to which economic empowerment improves women's dietary diversity and consumption of specific food items, and how this can influence the development of interventions that could directly improve women's dietary diversity.

\section{Acknowledgements}

Acknowledgements: The authors would like to thank Craig Janes and Suneetha Kadiyala for the critical comments on the manuscript as the lead author's thesis committee member and external examiner, and to the staff of the Nigerian Bureau of Statistics, for assisting with primary data collection. Financial support: The study was funded by the Graduate Student International Experience Award of the University of Waterloo. The funding body played no role in the design and conduct of the study. Conflict of interest: There are no conflict of interest. Authorship: M.N.O. and S.H. conceptualised the study, M.N.O. conducted the data collection and analyses, S.H. and J.H. provided critical guidance in data interpretation, M.N.O., S.H. and J.H. contributed to drafting of manuscript. All authors read and approved the final version before submission. Ethics of buman subject participation: Formal ethical approval was received from the University of Waterloo's Office of Research Ethics (\#32095) and research permission from Enugu State Ministry of Health (MH/MSD/ REC19/048). In addition, permission to conduct the study and collect data from participants was sought from local government authorities in sampled districts and wards in Nsukka LGA. Written consent was collected from the participants in the IDI and consent forms were translated into the local language (Igbo). To accommodate participants with poor literacy levels, the information sheet and consent forms were read and explained before consent was sought verbally and written by collecting the participant's thumbprint. All data and information remained strictly confidential and anonymous to protect the privacy of each participant. 


\section{References}

1. Duflo E (2012) Women empowerment and economic development. J Econ Lit 50, 1051-1079.

2. Kabir N (2016) Women's Economic Empowerment and Inclusive Growth: Labour Markets and Enterprise Development. UK: School of Oriental and African Studies.

3. Kabeer N (1999) Resources, agency, achievements: reflections on the measurement of women's empowerment. Dev Change 30, 435-464.

4. Kabeer N (2011) Between affiliation and autonomy: navigating pathways of women's empowerment and gender justice in rural Bangladesh. Dev Change 42, 499-528.

5. Masset E, Haddad L, Cornelius A et al. (2012) Effectiveness of agricultural interventions that aim to improve nutritional status of children: systematic review. BMJ 344, d8222.

6. Savy M, Martin-Prével Y, Traissac P et al. (2006) Dietary diversity scores and nutritional status of women change during the seasonal food shortage in rural Burkina Faso.J Nutr 136, 2625-2632.

7. Hoddinott J \& Yohannes Y (2002) Dietary diversity as a food security indicator. Food Consum Nutr Div Discuss Pap 136, 2002.

8. FAO (2021) Minimum Dietary Diversity for Women. Rome: FAO. http://www.fao.org/documents/card/en/c/ cb3434en (accessed May 2021).

9. Chakona G \& Shackleton C (2017) Minimum dietary diversity scores for women indicate micronutrient adequacy and food insecurity status in South African towns. Nutrients 9, 812.

10. Onah MN (2020) Approaches to Understanding and Measuring Women's Empowerment and Its Relationship with Women's and Children's Dietary Diversity in SubSaharan Africa. https:/uwspace.uwaterloo.ca/handle/ 10012/15732 (accessed June 2020).

11. Huang M, Sudfeld C, Ismail A et al. (2018) Maternal dietary diversity and growth of children under 24 months of age in rural Dodoma, Tanzania. Food Nutr Bull 39, 219-230.

12. Girma W \& Genebo T (2002) Determinants of the Nutritional Status of Mothers and Children in Ethiopia. DHS Further Analysis Reports no. 39. http://dhsprogram.com/pubs/pdf/ FA39/FA39.pdf (accessed June 2020).

13. Onah MN, Horton S \& Hoddinott J (2021) What empowerment indicators are important for food consumption for women? Evidence from 5 sub-Sahara African countries. PLoS One 16, e0250014.

14. Sen A (1987) Gender and Cooperative Conflicts. Helsinki, Finland: World Institute for Development Economics Research.

15. Harris-Fry H, Shrestha N, Costello A et al. (2017) Determinants of intra-household food allocation between adults in South Asia - a systematic review. Int J Equity Health 16, 107.

16. Ponthieux $S$ (2013) Income Pooling and Equal Sharing within the Household - What Can We Learn from the 2010 EU-SILC Module. European Commission. https://op.europa.eu/en/ publication-detail/-/publication/1e8fd3bf-aabf-4f43-91e7-b390 912c02ed (accessed June 2020).

17. Bonke J (2015) Pooling of income and sharing of consumption within households. Rev Econ Household 13, 73-93.

18. Watson D, Maître B \& Cantillon S (2013) Implications of Income Pooling and Household Decision-Making for the Measurement of Poverty and Deprivation: An Analysis of the SILC 2010 Special Module for Ireland. www.social inclusion.de/documens/2013-10-16b_IncomePoolingDec MakingRptFinal.pdf (accessed June 2020).

19. Phipps SA \& Burton PS (1998) What's mine is yours? The influence of male and female incomes on patterns of household expenditure. Economica 65, 599-613.

20. Duflo E \& Udry C (2004) Intrahousebold Resource Allocation in Cote d'Ivoire: Social Norms, Separate Accounts and
Consumption Choices. Cambridge, MA: National Bureau of Economic Research.

21. Onah MN \& Horton S (2018) Male-female differences in households' resource allocation and decision to seek healthcare in south-eastern Nigeria: results from a mixed methods study. Soc Sci Med 204, 84-91.

22. Doss CR (2002) Men's crops? Women's crops? The gender patterns of cropping in Ghana. World Dev 30, 1987-2000.

23. Obayelu AE, Ogbe AO \& Edewor SE (2019) Gender gaps and female labour participation in agriculture in Nigeria. Afr J Econ Manag Stud 11, 285-300.

24. Mangyo E (2008) Who benefits more from higher household consumption? The intra-household allocation of nutrients in China. J Dev Econ 86, 296-312.

25. World Food Programme (2020) Who Eats When, What and How Much? Understanding Intra-Household Food Patterns within Poor Households in Two Locations in Uttar Pradesh, India. https://docs.wfp.org/api/documents/ WFP-0000116367/download/?.ga=2.224136274.878977328. 1614956512-1202860145.1614956512 (accessed June 2020).

26. Gupta MD (1987) Selective discrimination against female children in rural Punjab, India. Popul Dev Rev 13, 77.

27. Gupta MD (1995) Life course perspectives on women's autonomy and health outcomes. Am Anthropol 97, 481-491.

28. Okehie-Offoha MU \& Sadiku MNO (1996) Ethnic and Cultural Diversity in Nigeria. Trenton, NJ: Africa World Press.

29. Bano M (2019) Religion and female empowerment: evidence from Pakistan and northern Nigeria. Can J Dev Stud 40, 163-181.

30. Hinchcliffe D (2017) Polygamy in traditional and contemporary Islamic law. In Issues in Islamic Law, pp. 63-78 [M Baderin, editor]. London, UK: Routledge.

31. Akseer N, Kamali M, Bakhache N et al. (2018) Status and drivers of maternal, newborn, child and adolescent health in the Islamic world: a comparative analysis. Lancet 391, 1493-1512.

32. Gupta S, Pingali P \& Pinstrup-Andersen P (2019) Women's empowerment and nutrition status: the case of iron deficiency in India. Food Policy 88, 101763.

33. Voufo BT, Uchenna E \& Atata SN (2017) Women empowerment and intra-household dietary diversity in Nigeria. $J$ Res Gend Stud 7, 39.

34. Kassie M, Fisher M, Muricho G et al. (2020) Women's empowerment boosts the gains in dietary diversity from agricultural technology adoption in rural Kenya. Food Policy 95 , 101957.

35. Galiè A, Teufel N, Girard AW et al. (2019) Women's empowerment, food security and nutrition of pastoral communities in Tanzania. Glob Food Sec 23, 125-134.

36. Meinzen-Dick RS, Rubin D, Elias M et al. (2019) Women's Empowerment in Agriculture: Lessons From Qualitative Research. Washington, DC: International Food Policy Research Institute.

37. National Population Commission (2006) The Nigeria Population Census 2006. http://www.population.gov.ng (accessed June 2020).

38. Enete AA \& Onyekuru AN (2011) Challenges of agricultural adaptation to climate change: empirical evidence from Southeast Nigeria. Tropicultura 29, 243-249.

39. National Bureau of Statistics (2013) General Household Survey Panel. https://nigerianstat.gov.ng/download/388 (accessed June 2020).

40. World Bank Group (2011) Nigeria: Socio Economic Assessment. http://documents.worldbank.org/curated/en/ 734001468292284454/pdf/706060ESW0P11700Assessment 0May2011.pdf (accessed June 2020).

41. Britten N (2006) Qualitative interviews. Qual Res Health care 3, 12-20. 
42. Fereday J \& Muir-Cochrane E (2006) Demonstrating rigor using thematic analysis: a hybrid approach of inductive and deductive coding and theme development. Int J Qual Methods 5, 80-92.

43. Cohen J (1968) Weighted $\kappa$ : nominal scale agreement provision for scaled disagreement or partial credit. Psychol Bull 70, 213.

44. Ajibade TB, Ayinde OE, Abdoulaye T et al. (2018) Determinants of price of Yam in Nigeria: a time-series analysis. Niger J Agric Econ 8, 109.

45. Odekunle TO (2004) Rainfall and the length of the growing season in Nigeria. Int J Climatol 24, 467-479.

46. Adepoju AO \& Adejare KA (2013) Food insecurity status of rural households during the post-planting season in Nigeria. J Agric Sustain 4, 16-34.

47. Bove R \& Valeggia C (2009) Polygyny and women's health in sub-Saharan Africa. Soc Sci Med 68, 21-29.

48. Malapit HJL \& Quisumbing AR (2015) What dimensions of women's empowerment in agriculture matter for nutrition in Ghana? Food Policy 52, 54-63.

49. Onah MN (2021) Women's empowerment and child nutrition in South-Central Asia; how important is socioeconomic status? SSM Popul Health 13, 100718.

50. Reardon T, Henson S \& Gulati A (2010) Links between supermarkets and food prices, diet diversity and food safety in developing countries. In Trade, Food, Diet and Health: Perspectives and Policy Options, pp. 111-130 [C Hawkes, C Boluin, C Henson et al., editors]. Chichester: Wiley-Blackwell.

51. Thorne-Lyman AL, Valpiani N, Sun K et al. (2010) Household dietary diversity and food expenditures are closely linked in rural Bangladesh, increasing the risk of malnutrition due to the financial crisis. J Nutr 140, 182S-188S

52. Pitt M \& Rosenzweig MR (1986) Agricultural prices, food consumption, and the health and productivity of Indonesian farmers. In Agricultural Household Models: Extensions, Applications and Policy, pp. 153-182 [I Singh, L Squire and J Strauss, editors]. Baltimore: Johns Hopkins University Press.

53. Afshin A, Peñalvo JL, Del Gobbo L et al. (2017) The prospective impact of food pricing on improving dietary consumption: a systematic review and meta-analysis. PLoS One 12, $\mathrm{e} 0172277$.

54. Andreyeva T, Long MW \& Brownell KD (2010) The impact of food prices on consumption: a systematic review of research on the price elasticity of demand for food. Am JPublic Health 100, 216-222.

55. Green R, Cornelsen L, Dangour AD et al. (2013) The effect of rising food prices on food consumption: systematic review with meta-regression. BMJ 346, 33703 .

56. Arimond M, Hawkes C, Ruel MT et al. (2011) Agricultural interventions and nutrition: lessons from the past and new evidence. In Combating Micronutrient Deficiencies: Food-Based Approaches, pp. 41-75 [B Thompson and L Amoroso, editors]. Oxfordshire: CAB International FAO.
57. King E \& Mason A (2001) Engendering Development: Through Gender Equality in Rights, Resources, and Voice. Washinton DC, USA: The World Bank.

58. Meinzen-Dick R, Behrman J, Menon P et al. (2012) Gender: a key dimension linking agricultural programs to improved nutrition and health. In Reshaping Agriculture for Nutrition and Health, pp. 135-144 [S Fan and R Pandya-Lorch, editors]. Washington DC, USA: IFPRI.

59. Akerele D, Sanusi RA, Fadare OA et al. (2017) Factors influencing nutritional adequacy among rural households in Nigeria: how does dietary diversity stand among influencers? Ecol Food Nutr 56, 187-203.

60. Malapit HJL, Kadiyala S, Quisumbing AR et al. (2015) Women's empowerment mitigates the negative effects of low production diversity on maternal and child nutrition in Nepal. J Dev Stud 51, 1097-1123.

61. Hamad R \& Fernald LCH (2012) Microcredit participation and nutrition outcomes among women in Peru. J Epidemiol Community Health 66, e1.

62. Ng'endo M, Bhagwat S \& Keding GB (2016) Influence of seasonal on-farm diversity on dietary diversity: a case study of smallholder farming households in Western Kenya. Ecol Food Nutr 55, 403-427.

63. Campbell RK, Talegawkar SA, Christian P et al. (2014) Seasonal dietary intakes and socioeconomic status among women in the Terai of Nepal. J Health Popul Nutr 32, 198.

64. Keding GB, Msuya JM, Maass BL et al. (2012) Relating dietary diversity and food variety scores to vegetable production and socio-economic status of women in rural Tanzania. Food Secur 4, 129-140.

65. Marriott BP, White A, Hadden L et al. (2012) World Health Organization (WHO) infant and young child feeding indicators: associations with growth measures in 14 low-income countries. Matern Child Nutr 8, 354-370.

66. Daelmans B, Dewey K \& Arimond M (2009) New and updated indicators for assessing infant and young child feeding. Food Nutr Bull 30, Suppl. 2, S256-S262.

67. Mohammed SH, Taye H, Larijani B et al. (2019) Food taboo among pregnant Ethiopian women: magnitude, drivers, and association with anemia. Nutr J 18, 19.

68. Chakrabarti S \& Chakrabarti A (2019) Food taboos in pregnancy and early lactation among women living in a rural area of West Bengal. J Fam Med Prim care $\mathbf{8}, 86$.

69. Santos-Torres MI \& Vásquez-Garibay E (2003) Food taboos among nursing mothers of Mexico. $J$ Health Popul Nutr 21, 142-149.

70. Sundararaj R \& Pereira SM (1975) Dietary intakes and food taboos of lactating women in a South Indian community. Trop Geogr Med 27, 189-193.

71. Ekwochi U, Osuorah CDI, Ndu IK et al. (2016) Food taboos and myths in South Eastern Nigeria: the belief and practice of mothers in the region. J Ethnobiol Ethnomed 12, 7. 